\title{
Risk attribution and interconnectedness in the EU via CDS data
}

\author{
R. Giacometti ${ }^{1,2}$ (D) G. Torri ${ }^{1,2} \cdot$ G. Farina ${ }^{3} \cdot$ M. E. De Giuli ${ }^{4}$
}

Published online: 19 January 2021

(C) The Author(s) 2021

\begin{abstract}
The global financial crisis in 2008, and the European sovereign debt crisis in 2010, highlighted how credit risk in banking sectors cannot be analysed from a uniquely micro-prudential perspective, focused on individual institutions, but it has instead to be studied and regulated from a macro-prudential perspective, considering the banking sector as a complex system. Traditional risk management tools often fail to account for the complexity of the interactions in a financial system, and rely on simplistic distributional assumptions. In recent years machine learning techniques have been increasingly used, incorporating tools such as text mining, sentiment analysis, and network models in the risk management processes of financial institutions and supervisors. Network theory applications in particular are increasingly popular, as they allow to better model the intertwined nature of financial systems. In this work we set up an analytical framework that allows to decompose the credit risk of banks and sovereign countries in the European Union according to systematic (system-wide and regional) components. Then, the non-systematic components of risk are studied using a network approach, and a simple stress-test framework is set up to identify the potential transmission channels of distress and risk spillovers. Results highlight a relevant component of credit risk that is not explained by common factors, but can still be a potential vehicle for the transmission of shocks. We also show that due to the properties of the network structure, the transmission of shocks applied to different institutions is quite diversified, both in terms of breadth and speed. Our work is useful to both regulators and financial institutions, thanks to its flexibility and its requirement of data that can be easily available.
\end{abstract}

Keywords Credit risk - Marshall-Olkin distribution · Risk attribution · Credit default swaps $\cdot$ Interconnectedness $\cdot$ Network theory $\cdot$ Stress test

The authors acknowledge the support of the Czech Science Foundation (GACR) under Project 19-11965S.

R. Giacometti

rosella.giacometti@unibg.it

Extended author information available on the last page of the article 


\section{Introduction}

The global financial crisis in 2008, and the European sovereign debt crisis in 2010, highlighted how credit risk in banking sectors cannot be analysed from a uniquely micro-prudential perspective, focused on individual institutions, but it has instead to be studied and regulated from a macro-prudential perspective, considering the banking sector as a complex system. Forecasting the development of systemic banking crises, and understanding the mechanisms that lead to such extreme scenarios (i.e. managing systemic risk), is fundamental for setting up macro-prudential supervisory policies and reducing the likelihood and intensity of such manifestations.

A first stream of literature aimed at assessing risk from a systemic perspective, focuses on the identification of common risk drivers, measuring the role of different factors in the determination of risk for different institutions using econometric techniques (see e.g. Ang and Longstaff 2013; Fontana et al. 2016; Fabozzi et al. 2016; Pianeti and Giacometti 2015; Alter and Schüler 2012; De Bruyckere et al. 2013; Kalbaskaa and Gatkowskiba 2012; Manzo and Picca 2020). Other works aim to quantify the systemic risk contribution or exposure for individual banks, among the most relevant, we can cite CoVaR (Adrian et Al. 2016), Systemic Expected Shortfall (Acharya et al. 2010), and Component Expected Shortfall (CES) (Dumitrescu et al. 2014).

Such approaches have the drawback of failing to account for the complexity of the interaction that happen in the financial system. Several contribution indeed stress the role of transmission of shocks across institutions, measuring contagion and risk spillovers (see e.g. Schwarcz 2008; Freixas et al. 2015; Covi et al. 2019). Moreover, these econometric approaches often rely on simplistic distributional assumptions, and do not allow to incorporate in the analysis the large amount of data available to practitioners and regulators. To tackle these issues, machine learning techniques can be used. In recent years many applications have been developed in the field of systemic risk and financial risk management (see Kou et al. 2019 for an extended review). Several contributions are focused on the inclusion of big data in risk management processes using text mining and sentiment analysis (O'Halloran et al. 2015; Cerchiello and Giudici 2016), on the parsing of large amount of financial and non-financial data to improve risk management in financial institutions (Lichters et al. 2014), or in the analysis of regulatory policies to manage systemic risk (O'Halloran et al. 2019). The most relevant machine learning applications to systemic risk and contagion analysis however is related to network models: the intertwined nature of financial systems makes indeed network analysis a fundamental tool to identify the most relevant institutions in a system and to study the exposures that are more relevant in the generation and the transmission of systemic risk. Several contributions use regulatory data and epidemiological methods to assess the diffusion of shocks in complex financial systems (Gai and Kapadia 2010; Puliga 2014; Covi et al. 2019). Yu et al. (2020) simulate an interbank network using balance sheet data of banks to identify if the financial institutions have sufficient capital reserves to prevent risk contagion and identify the synthetic features of the network. Moreover, in absence of granular bilateral data, other works aim to estimate the network structure using the market prices of traded securities. Examples are Billio et al. (2012) that use Granger-causality networks to identify and forecast financial 
instability periods, Diebold and Y1lmaz (2014) that consider variance decomposition to track the interconnectedness of major US companies, and Anufriev and Panchenko (2015) and Torri et al. (2018) that rely on partial correlation networks to characterize the structure of the banking systems. The adoption of network models is high on the agenda of regulators: the Basel Committee on Banking Supervision (in the following BCBS) has identified the "excessive interconnectedness among systemically important banks" as one of the weakness of the European financial system and it has made addressing the systemic risk created by this interconnectedness a cornerstone of Basel III. Indeed Basel III established a higher loss absorbency requirement for institutions deemed to be global systemically-important banks (G-SIBs), (see BCBS 2011). The development of methodologies to estimate the network structure and assess the transmission of risk becomes then increasingly relevant. In this work we aim to study the systemic dimension of credit risk in the European banking sector, considering both the presence of systematic risk components (system-wide and regional), and the role of direct transmission of shocks adopting a network perspective, after controlling for the systematic components. More in detail, we first apply the model of Farina et al. (2019) to credit default swaps (CDS) spreads data for European banks to identify the systematic components using Marshall-Olkin multivariate distribution(Marshall and Olkin 1967), and then we analyze the interactions of the idiosyncratic components to consider the potential spillovers of risk by considering network indicators and a contagion model for the transmission of distress inspired to Puliga (2014). Conceptually, our framework is related to the analysis of Brownlees et al. (2018), that studies the network structure of a panel of American blue chips by using equity returns, first fitting a linear factor model to the returns, and then estimating partial correlation networks on the residuals, in order to avoid measuring spurious connections. Differently from such work, our analysis does not rely on Gaussian assumption, and in our opinion is therefore more suitable for the analysis of credit spreads. Moreover, instead of considering principal components, our factor analysis focuses on meaningful country and industry sectors, allowing a greater intepretability of the results. This framework allows us to investigate credit risk in a systemic perspective, measuring both the role of common factor and the network structure of the non-systematic component, going beyond traditional econometric analysis and focusing on the network structure of the system. The analysis is conducted on eight countries in the European Union (EU), whose banking system is modelled using a set of twenty-nine representative banks. ${ }^{1}$ We assume that the default of each country can be due to three possible systematic factors or components: a common EU factor, a banking/country specific component and a country specific factor. After controlling for these factors, we identify a residual components, that is used to construct correlation-based networks. The main contribution of this paper is the development of a unified framework to study systemic and systematic risk in a banking system, considering non-Gaussian distributional assumption, and network models.

\footnotetext{
1 Banking and financial system refer respectively to the services provided by banking and non-banking financial institutions. The main difference between the two is that non-banking financial institutions cannot take deposits from customers like traditional banks do. On the contrary financial companies provide other services than banking institutions, which include asset management and insurance services. In this paper, while still aware of the difference, we use financial system as a synonymous of banking system.
} 
The paper is structured as follows: in Sect. 2 we present our model and introduce the network analysis framework. In Sect. 2.1 we describe the data and discuss the results. Section 2.2 provides our conclusions.

\section{The proposed methodology}

The main purpose of this section is to illustrate the methodology used to decompose the credit risk of the most representatives banks in EU. Credit risk is attributed to systematic components, related to system-wide and regional factors, and a residual non-systematic (idiosyncratic) component is identified. For the decomposition we assume a Marshall-Olkin distribution (Marshall and Olkin 1967) to attribute risk according to different kinds of shock.

\subsection{The risk decomposition model}

A framework suitable to describe such system of shocks is the Marshall-Olkin multivariate distribution (see e.g. Giesecke 2003; Mai et al. 2016). In our framework, we consider a reduced-for model where the components are private and public entities, and the failures are default events involving the entire system, the sovereign states, the national banking systems or combinations of these. The model, described in greater details in Farina et al. (2019), extends Baglioni and Cherubini (2013) to a multivariate framework and introduces a new cross country component that identifies the systematic EU-wide risk, related to shocks that affect the entire financial system and cannot be diversified.

Let introduce the proposed framework with a toy example. Assume that there are $n=2$ entities and $p=3$ possible shocks. Shock $k$ is modeled as an independent Poisson process $N_{k}$, with intensity $\lambda_{k}$. The two entities are usually indicated as 1 and 2 and the three shocks are indicated as 1,2 and $\{1,2\}$.

The marginal random variables are exponentially distributed with $\lambda_{1}+\lambda_{\{1,2\}}$ and $\lambda_{2}+\lambda_{\{1,2\}}$ being the rates of failure of the two entities. The default times are positively correlated with a Spearman correlation coefficient ${ }^{2}$ computed as:

$$
\rho_{s}=\frac{3 \lambda_{\{1,2\}}}{2 \lambda_{1}+2 \lambda_{2}+3 \lambda_{\{1,2\}}} .
$$

Let's indicate with $\tau_{j}$ the default time of entity $i$ and with $\bar{F}_{i}$ its survival function,

$$
\bar{F}_{i}(t)=P\left[N_{i}(t)+N_{\{1,2\}}(t)=0\right]=e^{-\left(\lambda_{i}+\lambda_{\{1,2\}}\right) t} .
$$

and the joint survival probability is

$$
\bar{F}(t, s)=P\left[\tau_{1}>t, \tau_{2}>s\right]=e^{-\lambda_{1} t} \cdot e^{-\lambda_{2} s} \cdot e^{-\lambda_{\{1,2\}} \max (t, s)} .
$$

\footnotetext{
${ }^{2}$ Spearman correlation coefficient $\rho$ is a measure of non-parametric rank correlation, that assesses how well the relationship between two variables can be described using a monotonic function (see Wayne 1990, pp. $358-365)$. 
Table 1 Classes of shocks and risk components

\begin{tabular}{ll}
\hline Type of shock & Risk component \\
\hline $\begin{array}{l}\text { Idiosyncratic default of public sector of } \\
\text { country } j\end{array}$ & $\lambda_{C_{j}}$ \\
$\begin{array}{l}\text { Default of the financial system of country } j \\
\text { Joint default of banking system and public }\end{array}$ & $\lambda_{F_{j}}$ \\
sector of country $j$ & $\lambda_{\left\{F_{j}, C_{j}\right\}}$ \\
$\begin{array}{l}\text { Idiosyncratic default of the bank } i \\
\text { Systemic event common to all countries and } \\
\text { financial systems in EU }\end{array}$ & $\lambda_{B_{i, j}}$ \\
\hline
\end{tabular}

Assume now that there are $n \geq 2$ entities; in this case, the number of all possible shocks is $2^{n}-1$. However, from a parsimonious point of view we concentrate our attention on a set with cardinality $p$ of shocks that are meaningful from an economic point of view and the dependency among the $n$ entities is explicitly modelled by the common exposure to some of the shocks rather than introducing a dependency structure upon the shocks themselves. In order to determine which shock will affect which entity, let us introduce a matrix $\left[a_{j, k}\right]_{n \times m}$ where $j=1, \ldots, n, k=1, \ldots, p$ whose elements have binary values, i.e. $a_{j, k}=1$ if entity $j$ is affected by shock $k$ otherwise zero.

The time to default of entity $j$ can be written as

$$
\tau_{j}=\inf \left\{t \geq 0: \sum_{k=1}^{p} a_{j, k} N_{k}(t)>0\right\}
$$

meaning that entity $j$ defaults as soon as any of the Poisson processes for which $a_{j, k} \neq 0$ exhibits a jump.

Using the independence assumptions among the shocks, it can be seen that entity $j$ has a default intensity equal to $\sum_{k=1}^{p} a_{j, k} \lambda_{k}$ or

$$
\bar{F}_{j}(t)=e^{-\sum_{k=1}^{p} a_{j, k} \lambda_{k} t}
$$

where $\lambda_{k}$ denotes the rates of failure of the $k$ th combination of entities. The multivariate joint survival probability is instead given by

$$
\bar{F}\left(t_{1}, \ldots, t_{n}\right)=e^{-\sum_{k=1}^{p} \lambda_{k} \cdot \max \left(a_{1, k} t_{1}, \ldots, a_{n, k} t_{n}\right)} .
$$

Within this framework, we model the EU as a set of $n$ countries and the related $n$ banking systems, where the $j$ th system is composed of $m_{j}$ banks. We consider five different classes of shocks, each one associated with a component of credit risk, as presented in Table 1.

Considering these shocks and their decomposition we model the survival probability of countries, banks and national financial systems (see Farina et al. 2019). In this paper we concentrate our attention at banking level since we want to analyse the bank 
interconnectedness once that we have removed the systematic components. In other words, before investigating the network of banks we need to isolate the idiosyncratic components of risk.

Analysing country $j$, we have $m_{j}$ banks which, collectively, can be seen as representative of its entire financial system. The marginal survival probability of the $i$ th bank in country $j, B_{i, j}$ with $i=1: m_{j}$ is:

$$
P\left[\tau_{B_{i, j}}>t\right]=e^{-\hat{\lambda}_{B_{i, j}} t}
$$

where

$$
\hat{\lambda}_{B_{i, j}}:=\lambda_{B_{i, j}}+\lambda_{F_{j}}+\lambda_{\left\{F_{j}, C_{j}\right\}}+\lambda_{E U}
$$

Hence the default intensity of each bank $B_{i, j}$ is related respectively to the idiosyncratic default of the bank $\lambda_{B_{i, j}}$, the default of the financial system of the country $\lambda_{F_{j}}$, the joint default of national banking and sovereign $\lambda_{\left\{F_{j}, C_{j}\right\}}$ and a common credit event in all EU i.e. $\lambda_{E U}$.

Moreover we identify the possible shocks of the country $j$ and its financial sector defining the default intensities as

$$
\begin{aligned}
& \hat{\lambda}_{C_{j}}:=\lambda_{C_{j}}+\lambda_{\left\{F_{j}, C_{j}\right\}}+\lambda_{E U}, \\
& \hat{\lambda}_{F_{j}}:=\lambda_{F_{j}}+\lambda_{\left\{F_{j}, C_{j}\right\}}+\lambda_{E U} .
\end{aligned}
$$

The economic interpretation is that a country and its financial sector can experience a default for three reasons: the country (or respectively its financial sector) is individually in default, the country and its financial system are jointly in default or all the countries in the EU experience a common default.

Equations (6), (7) and (8) are the principal relationships in our decomposition model which we apply to isolate the idiosyncratic components $\lambda_{B_{i, j}}$ of each bank from all the possible other components in order to avoid spurious correlation effects. The estimation procedure is described in "Appendix A".

\subsection{Network analysis}

The risk decomposition presented so far is based on the assumption that all the possible shocks in the financial system belong to one of the categories listed in Table 1. This restriction is necessary for the interpretability of the results and for the estimation of the model: if we considered all the possible combinations, the number of different shock types would amount to $2^{n+m}-1$, where $n$ is the number of banks in the sample and $m$ the number of countries.

The different non-systematic components identified by the model are not necessarily independent and, on the contrary, they include relevant information related to systemic risk in terms of contagion and spillover effects. 
We analyze these features using network theory, representing banks as nodes of a network $\mathcal{G}$ constructed using the correlation of idiosyncratic components $\lambda_{B_{i, j}}$ of each bank.

Let $\mathcal{G}=(\mathcal{V}, \mathcal{E})$ be a graph where $\mathcal{V}$ is the vertex or node set of cardinality $N$ and $\mathcal{E}$ is the set of the edges. We assume that the network is a proxy of interdependencies among banks where each bank is a node and we assign a link or edge between a pair of banks at time $t$ if the co-movements of the two time series of intensity variations show a significant Spearman correlation.

Let $B$ be the adjacency matrix where each entry $b_{i, j}$ records the existence of the link between nodes $i$ and $j$. The matrix $B$ is assumed to be symmetric (i.e. the graph is undirected) and the elements are equal to the Spearman correlation coefficient between each pairs of banks within and between each couples of countries.

We then characterize the network using a set of indicators, in particular we consider the density of the network (defined as the number of edges in the network divided by all the possible ones) and two centrality indicators (strength centrality and eigenvector centrality). A centrally located bank is likely to be systemically important, as it has the potential to affect a large part of the network directly or indirectly in case of a shock.

There is a range of ways to quantify the nodes centrality. Degree centrality is the simplest way to measure the importance of nodes, as it relies only on the local structure around them; it is computed as the number of links a node has. A natural extension of degree centrality is the strength centrality. The strength centrality indicator assumes that the node importance is given by the sum of weights of the links connected to it.

Another measure of centrality of a node is the eigenvector centrality. It is a feedback centrality measure, based on the idea that some nodes are more relevant than others. It is indeed based on the principle that connections to few high scoring nodes contribute more to the score than connections to low scoring nodes. Formally the $i$ th node centrality score $x_{i}$ is proportional to the sum of the scores of all the nodes which are connected to it. The centrality score $x_{i}$ of the $i$ th node is defined as:

$$
x_{i}=\frac{1}{\lambda} \sum_{j=1}^{N} b_{i, j} x_{j},
$$

where $N$ is the number of nodes in the graph, $\mathcal{N}(i) \subseteq \mathcal{V}$ is the set of neighbours of $i$ and $\lambda$ is a constant.

Equation (9) can be rewritten in a more compact form as the eigenvector equation:

$$
B x=\lambda x \text {. }
$$

Assuming that the graph is connected, it follows from the Perron-Frobenius theorem that for $\lambda$ being the largest eigenvalue of the adjacency matrix $B$, and $x$ the corresponding eigenvector, all the entries of $x$ are non-negative and correspond to the centralities of the nodes (see Newman 2010, p. 169).

The eigenvector centrality differs from the previous centrality indicators: a node receiving many links does not necessarily have a high eigenvector centrality (it might be that all linkers have low or null eigenvector centrality). Moreover, a node with high 
eigenvector centrality is not necessarily characterized by a large number of edges (the node might have few but important links).

Finally we perform a stress-test based on DebtRank (see Puliga 2014). DebtRank allows to estimate the systemic impact of a shock to a node in the network. In this work, we focus on a small shock hitting individual banks and we want to measure the final effect, due to the shock reverberations through the network.

We define the impact of node $i$ on node $j$ as $\alpha \cdot b_{i, j}$, where $b_{i, j}$ is the weight of the link in the network and $\alpha$ is a parameter that controls the intensity of the impact. The impact of $i$ on its first neighbours is $\sum_{j} b_{i, j} v_{j}$, where $v_{j}$ is a measure of the economic size of $j$. Similarly to Puliga (2014) we take $v_{j}=1, \forall j$.

We associate to each node two state variables: a continuous variable $h_{i} \in[0,1]$ and a discrete variable $s_{i} \in\{U, D, I\}$ i.e. with 3 possible states: undistressed, distressed, inactive.

Denoting by $S_{f}$ the set of nodes in distress at time 1, the initial conditions are:

- $h_{i}(1)=\Psi \quad \forall i \in S_{f}$ and $h_{i}(1)=0 \quad \forall i \notin S_{f}$,

- $s_{i}(1)=D \quad \forall i \in S_{f}$ and $s_{i}(1)=U \quad \forall i \notin S_{f}$.

where the parameter $\Psi$ measures the initial level of distress, $\Psi \in[0,1]$ with $\Psi=1$ meaning default.

The dynamics is defined as follows for all $i$ :

$$
h_{i}(t)=\min \left\{1, h_{i}(t-1)+\sum_{j \in \mathcal{J}}\left(b_{j i}\right)^{+} h_{j}(t-1)\right\},
$$

where $\mathcal{J}$ is the set of nodes $j$ with $s_{j}(t-1)=D$ and

$$
s_{i}(t)=\left\{\begin{array}{ll}
D & \text { if } h_{i}(t)>0, s_{i}(t-1) \neq I, s_{i}(t-1) \neq D \\
I & \text { if } s_{i}(t-1)=D \\
s_{i}(t-1) & \text { otherwise }
\end{array},\right.
$$

where $b_{j i}^{+}$is defined as $\max \left\{0, b_{j i}\right\}$ and denotes the positive edges in the network. ${ }^{3}$ After a finite number of steps $\mathrm{T}$ the dynamics stop and all the nodes in the network are either in state $\mathrm{U}$ or I.

The DebtRank of the set $S_{f}$ is then defined as

$$
R=\sum_{j} h_{j}(T) v_{j}-\sum_{j} h_{j}(1) v_{j}
$$

It can be interpreted as the amount of distress induced in the system by the reverberation of the initial shock.

\footnotetext{
${ }^{3}$ Note that we are using a slight modification of the model in Puliga (2014). The difference is that in this work we considered only the positive edges in the network as a channel for the diffusion of distress. This is motivated by the fact that, in case of a sudden shock hitting of a bank, it would make poor economic sense to model a reduction in other banks distress, even if historically they have an edge (connection) with a negative sign.
} 
In our work we analyse the effect of shocks hitting individual banks, in particular we consider small shocks with magnitude $\alpha=0.1$. This framework could be used also for the simulations of shocks of different magnitudes and to shocks hitting multiple institutions.

\section{Decomposition results and network analysis}

In this section we present the data and the results obtained applying the model described in Sect. 2. In particular, we first analyse the intensity of the common factor $\lambda_{E U}$ and then move to allocate risk to the different components. Finally we investigate the network of banks constructed using the idiosyncratic components of risk.

\subsection{Data}

A credit default swap (CDS) is a bilateral a contract, with the credit protection buyer paying a periodic fee in return for receiving compensation in case the reference entity should experience a credit event during the contract's life. Hence CDSs allow to isolate and price the credit risk of the reference entity. In order to perform our analysis on credit risk attribution in EU, we consider CDS data where the reference entities are the following countries: UK, Germany, France, Netherlands, Italy, Portugal, Greece and Spain.

This country selection is in line with previous researches (see e.g. Reboredo and Ugolini 2015; Fabozzi et al. 2016; Pianeti and Giacometti 2015; Alter and Schüler 2012; Baglioni and Cherubini 2013; Kalbaskaa and Gatkowskiba 2012). We also point out that our banks' selection is consistent with the European Banking Authority (EBA) stress-test excercise, proving that our data are representative of the banking system of the relative countries. ${ }^{4}$

We divide the countries in two subsets: northern countries composed by UK, Germany, France, Netherlands, and southern countries: Italy, Portugal, Greece and Spain. For each country we consider the banking system which is composed, at least, by two banks. $^{5}$

Our sample consists of daily observations of 5-years CDS quotes for European sovereign and banks' CDS from 06-Nov-2008 to 18-Sep-2014 (1532 observations in total) downloaded from Datastream. We perform our analysis on both daily and weekly data but report the result for weekly data for brevity (307 observations in total). Data series of sovereign CDS are plotted in Fig. 1. In Tables 2 and 3 we report the descriptive statistics for each country and the relative banks used as proxies of the banking systems. We observe that, apart from Greece, the average sovereign CDS quotes are smaller than the banks' ones, with a smaller standard deviation. In general, the behaviour of the banks in a country is very heterogeneous.

\footnotetext{
4 We observe that apart from Rabo Bank Group in Netherlands, Espirito Santo in Portugal and Caja Madrid in Spain, all the others were involved in the last stress-test exercise of the European Banking Authority.

5 We respected this constraint in the selection of the countries from the available dataset and we discarded the countries with less then two banks because we cannot apply the estimation procedure described in Farina et al. (2019).
} 

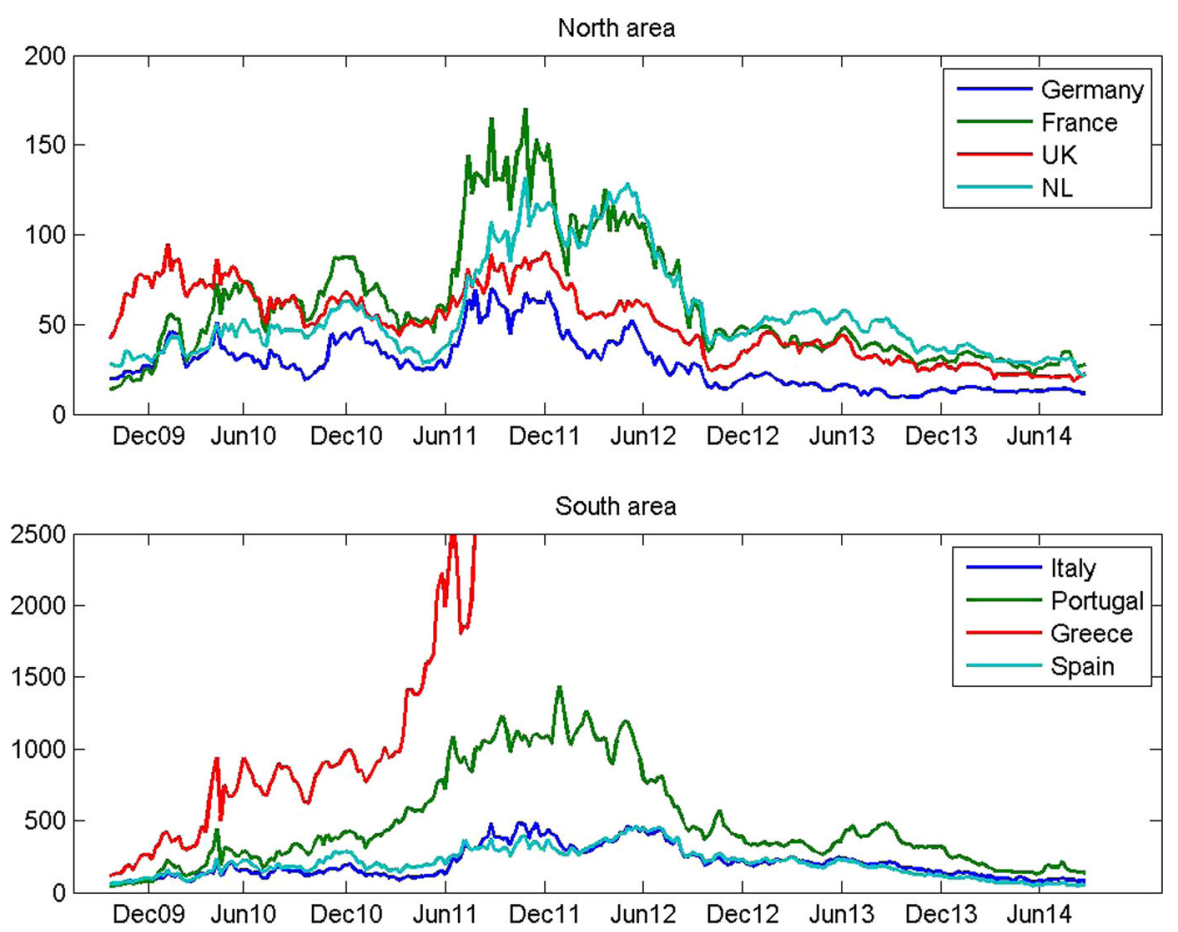

Fig. 1 Cds quotes for $5 \mathrm{Y}$ maturity for the period included in the study for the northern countries (top) and southern ones (bottom)

\subsection{Banking risk attribution}

One of the main advantages of using the modeling framework introduced in Sect. 2 is the ability to allocate risk to the different components in an intuitive way, thanks to the additive nature of each of the introduced relationships (Eqs. 6, 7, 8). In this paper we focus our analysis on banking level. By looking at Eq. (6) it is possible to split the individual bank risk in four components: idiosyncratic, banking and public sector,specific financial sector and common EU components. Table 4 reports the average weights for these decompositions (grouped at national level). Two things can be noticed: (i) a low weight assigned to the common $E U$ component and a high relevance of individual default, (ii) a different composition of risk between northern and southern countries.

The former suggests that the preeminent source of risk at banking level is related to countries and idiosyncratic factors more than to common shocks. The latter suggests that northern banks have a higher exposition to either idiosyncratic or banking system shocks without affecting the country. Southern banks are more exposed to a joint default of the banking system and country, suggesting a deeper link between public and private sectors.

Figure 2 reports the evolution over time of the average decomposition for individual banks, computed on rolling windows of 50 days. The graph highlights how in the crisis period (2009-2012), the relevance of idiosyncratic component is on average 
Table 2 Descriptive statistics - northern countries

\begin{tabular}{llrrrr}
\hline Country & Bank & Mean & \multicolumn{1}{c}{ SD } & Skewness & Kurtosis \\
\hline Germany & & 30.23 & 16.29 & 1.03 & 3.85 \\
& Bayerische L. Bank & 367.49 & 154.54 & 1.33 & 4.32 \\
& Nordbank & 217.99 & 63.96 & 1.07 & 3.51 \\
& Commerz Bank & 358.07 & 195.09 & 0.93 & 3.25 \\
& Deutsche Bank & 192.23 & 74.96 & 1.07 & 3.61 \\
France & & 58.13 & 33.70 & 1.14 & 3.63 \\
& Societè General & 267.87 & 164.23 & 1.17 & 3.38 \\
& Credit agricole & 269.71 & 155.23 & 0.96 & 2.99 \\
& BNP & 213.59 & 130.83 & 1.30 & 3.68 \\
UK & & 56.77 & 26.91 & 1.05 & 4.72 \\
& Lloyds & 325.38 & 155.09 & 0.76 & 2.91 \\
& Barclays & 242.57 & 107.71 & 0.79 & 2.70 \\
& HSBC & 138.36 & 48.73 & 0.98 & 3.21 \\
& Royal Bank of Scotland & 290.27 & 133.65 & 0.54 & 2.81 \\
Netherlands & & 57.07 & 27.94 & 1.11 & 3.04 \\
& SNS Bank & 392.48 & 155.47 & 0.45 & 2.58 \\
& RABO Bank & 133.18 & 43.85 & 0.89 & 3.12 \\
& ING Bank & 203.15 & 91.59 & 0.91 & 3.08 \\
\hline
\end{tabular}

lower while the importance of public and banking factor is higher when compared to the rest of the period. These two trends are more marked for southern countries, indicating that in the crisis period, banks in southern countries were more exposed to a joint default of public and banking sector. One important aspect to underline is that, in general, the exposure to common and country shocks can not fully explain the credit risk of banks, since the idiosyncratic component accounts on average for more than $40 \%$ of the CDS spread. This consideration, together with the fact that idiosyncratic components are not independent, motivates the next section of the paper, in which we analyse the interdependence structure using a network approach.

\subsection{Network analysis: banks interconnectedness}

Assuming that co-movements between idiosyncratic $\lambda_{B_{i, j}}$ are proxies of interdependencies among financial institutions, we examine the network properties of the banking system.

We represent banks as the nodes of the network. For each week $t$, we assign a link between a pair of banks if the co-movements of the two time series of length $\mathrm{T}$ show a significant correlation in the period $[(t-T),(t-1)]$, with $T=75$ weeks. For the statistical validation of the edges we rely on the empirical distribution of the correlations in the network. In particular we calculate the 97.5 th and 2.5 th percentile of the $\rho$ distribution of samples obtained randomly extracting 10,000 sample of size 75 from 
Table 3 Descriptive statistics—-southern countries

\begin{tabular}{|c|c|c|c|c|c|}
\hline Country & Bank & Mean & SD & Skewness & Kurtosis \\
\hline \multirow[t]{5}{*}{ Italy } & & 186.69 & 106.36 & 1.09 & 3.32 \\
\hline & UBI & 365.39 & 228.92 & 0.87 & 2.75 \\
\hline & MPS & 566.31 & 364.72 & 0.35 & 1.68 \\
\hline & Intesa & 327.41 & 208.60 & 0.88 & 2.77 \\
\hline & Unicredit & 388.05 & 226.71 & 0.85 & 2.79 \\
\hline \multirow[t]{3}{*}{ Portugal } & & 411.01 & 342.86 & 1.11 & 3.10 \\
\hline & Espirito Santo & 643.52 & 389.44 & 0.62 & 2.62 \\
\hline & Comr Portugues & 723.22 & 521.62 & 0.78 & 2.57 \\
\hline \multirow[t]{4}{*}{ Greece } & & 7407.16 & 6874.71 & 0.10 & 1.09 \\
\hline & Alpha & 1443.61 & 1001.99 & 1.13 & 3.41 \\
\hline & Ergasias & 1287.25 & 573.13 & -0.54 & 1.62 \\
\hline & National Bank & 1208.38 & 516.78 & -0.35 & 1.98 \\
\hline \multirow[t]{7}{*}{ Spain } & & 184.60 & 101.45 & 0.70 & 2.79 \\
\hline & Bankinter & 331.77 & 175.70 & 1.03 & 3.25 \\
\hline & Sabadell & 587.67 & 322.37 & 0.90 & 3.03 \\
\hline & Popular Espn & 1016.35 & 645.20 & 0.50 & 1.71 \\
\hline & Caja Madrid & 680.66 & 325.95 & 2.19 & 9.86 \\
\hline & BBVA & 339.95 & 191.52 & 0.64 & 2.44 \\
\hline & Santander & 311.18 & 166.90 & 0.57 & 2.26 \\
\hline
\end{tabular}

Table 4 Aggregated banks decomposition (summary)

\begin{tabular}{|c|c|c|c|c|}
\hline & $\omega_{\lambda_{B_{j}}}(\%)$ & $\omega_{\lambda_{\left\{F_{j}, C_{j}\right\}}}(\%)$ & $\omega_{\lambda_{F_{j}}}(\%)$ & $\omega_{\lambda_{E U}}(\%)$ \\
\hline Germany & 60.79 & 2.27 & 29.84 & 7.10 \\
\hline France & 15.90 & 15.08 & 60.77 & 8.25 \\
\hline UK & 49.04 & 8.67 & 34.43 & 7.86 \\
\hline Netherland & 50.87 & 12.99 & 28.11 & 8.03 \\
\hline North & 44.15 & 9.75 & 38.29 & 7.81 \\
\hline Italy & 26.89 & 35.16 & 32.10 & 5.85 \\
\hline Portugal & 8.45 & 42.77 & 45.36 & 3.43 \\
\hline Greece & 42.29 & 43.60 & 12.50 & 1.61 \\
\hline Spain & 68.92 & 15.84 & 11.19 & 4.04 \\
\hline South & 36.64 & 34.34 & 25.29 & 3.73 \\
\hline Total & 40.39 & 22.04 & 31.79 & 5.77 \\
\hline
\end{tabular}

Columns 1, 2,3 and 4 show the average weights of the different components of the banks risk for northern and southern countries (see Eq. 6) 


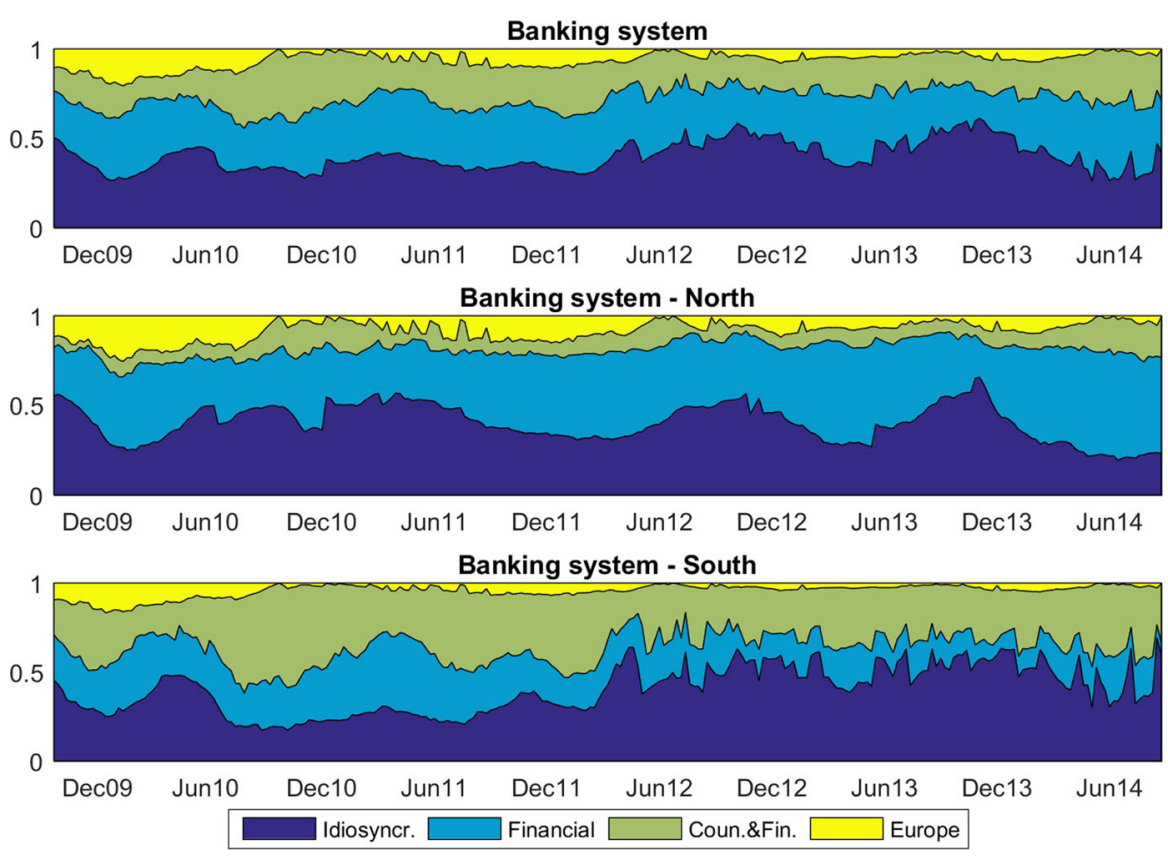

Fig. 2 Evolution over time of banks' risk decomposition. The three graphs show, in order, the average over the entire system, over northern countries and southern ones

the original populations. The correlation between two time series to be significant must be larger than 97.5 th percentile or below the 2.5 th percentile. We obtain 235 correlation matrices and we study the evolution over time of the set of interconnectedness indicators: density, group DebtRank, strength and eigenvector centrality.

We construct the network on the idiosyncratic $\lambda s$ since we expect they would reflect more accurately the real interdependence structure of the banks.

Networks based on raw data would fail to proxy the channel of diffusion of contagion, since they would be influenced by the common exposures to the same factors. ${ }^{6}$

We assume that exposures to common assets is captured by the different components of $\lambda s$ that we identified previously, leaving the residual idiosyncratic components as more reliable proxies of the channels for contagion.

For comparative purposes we also build and analyse networks using intensity of default $\hat{\lambda}_{B_{i, j}}$ directly derived by bootstrapping the banks CDSs (in this section of the paper we refer to these as raw data networks, in alternative to idiosyncratic networks).

Figure 3 reports the evolution over time of some relevant network indicators (for easier interpretation we grouped banks according to their country).

We notice that the idiosyncratic networks are less dense compared to the raw data networks, and their nodes have on average a smaller strength. This is in line with our assumption that a part of the interaction between banks is captured by the common and country factors.

\footnotetext{
6 The exposures to common assets according to Hurd (2015) may have the effect of weakening the stability of the system, but do not exhibit the amplification effect that characterizes contagion.
} 

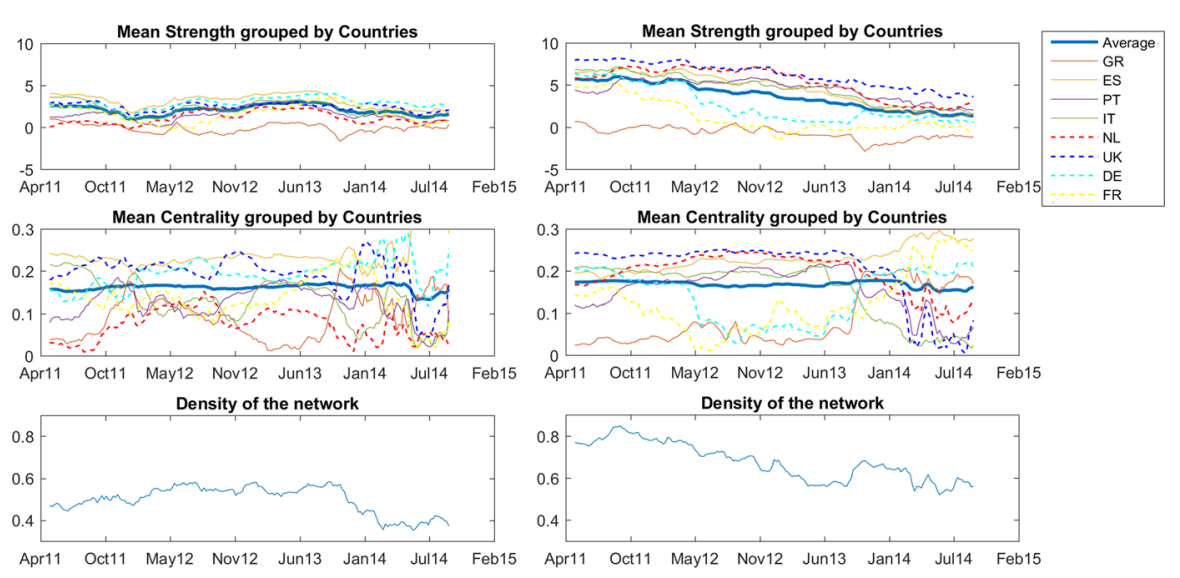

Fig. 3 Banks interconnectedness indicators computed on idiosyncratic components (left) and raw data (right)

The raw data networks show a clear decreasing pattern in terms of mean strength and network density, while the idiosyncratic networks do not. An interpretation is that the higher interconnectedness registered during the crisis in raw data networks can be explained considering the exposures to external risk factors such as sovereign risk, and not to an increased mutual exposure of the banks.

We notice that the Greek banks have the lowest strength, both considering the idiosyncratic $\lambda s$ and the raw ones. This could be consistent with a negative expectation on the creditworthiness of Greek banks, that lead to a small influence on the financial system of a potential default. In the idiosyncratic networks Dutch and French banks tend to have a lower-than-average strength, while Spanish, German and UK banks are the most connected in terms of strength.

Finally, considering eigenvector centrality, we note that Greek and Dutch banks score generally lower than the average while German and Spanish banks are usually above it. The pattern however is less clear.

The properties of the banking network can be further analysed conducting simulated stress-tests inspired by DebtRank framework (Puliga 2014). In particular, we hit individual banks with small shocks and we analyse the diffusion over the entire network.

Although the stress-test methodology is largely simplified, as it does not take into consideration parameters such as the relative size of the banks in the system or the composition of their balance sheets, this methodology allows to separate the network effects from other factors and uses readily available data, allowing banks and regulators to monitor the risks more accurately and implement effective precautionary measures. We focus our analysis on two periods: Jan 2010-Jun 2011 (within the European sovereign crisis) and Jan 2013-Jun 2014 (after the most acute phase of the crisis). For brevity we consider only shocks hitting four different banks: Alpha Bank (Greece), Unicredit (Italy), ING (Netherlands) and Deutsche Bank (Germany).

Figure 4 reports the effects of a small shock hitting individual banks and propagating through the network: height of the bars represents the amount of distress and colour 

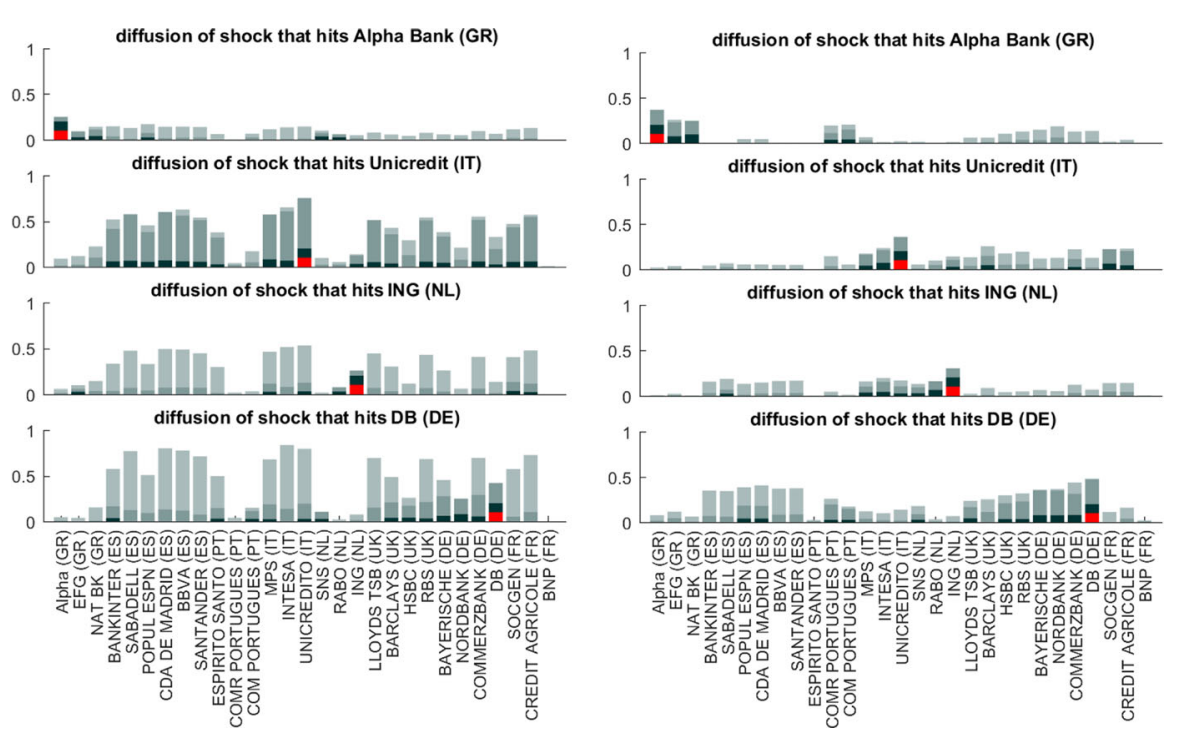

Fig. 4 DebtRank stress-test. The graphs represent the amount of distress transmitted to the system as a consequence of a small shock hitting a single bank. The shocked bank is highlighted in red. Dark color indicates distress transmitted in the early phases of the contagion (color figure online). Graphs on the left refer to the period 2010-Jun 2011, while graphs on the right to Jan 2013-Jun 2014

represent the temporal diffusion (darker parts denotes distress transmitted in early stages). Figure 5 reports the amount of total distress at different time stages of the stress-test.

We see that the amount of distress created in the system varies a lot across different time periods. During the crisis period the contagion is much more intense and is more acute for Mediterranean countries, while in the post-crisis the diffusion is less intense and more spread across geographical regions. From Fig. 5 we can also notice different diffusion patterns: for instance in the crisis period the shock hitting Deutsche Bank causes little distress in the first stages of diffusion, but then explodes in the fourth stage. On the other hand, according to the model, a shock hitting Unicredit has a faster but less intense propagation. This framework can therefore help to identify the most risky banks for the financial contagion both in terms of entity of the impact and speed of the diffusion, providing interesting insights in terms of regulation policies.

\section{Conclusions}

In this work we present a modeling framework for assessing the role of systematic components in CDS sovereign and banking markets, concentrating our attention on the banking level, and to estimate the network structure of the non-systematic component of risk. The methodology is highly tractable and customizable by virtue of using Marshall-Olkin distribution, and allows to go beyond the ubiquitous Gaussian assumptions. Moreover, the usage of network analysis for studying the non-systematic 

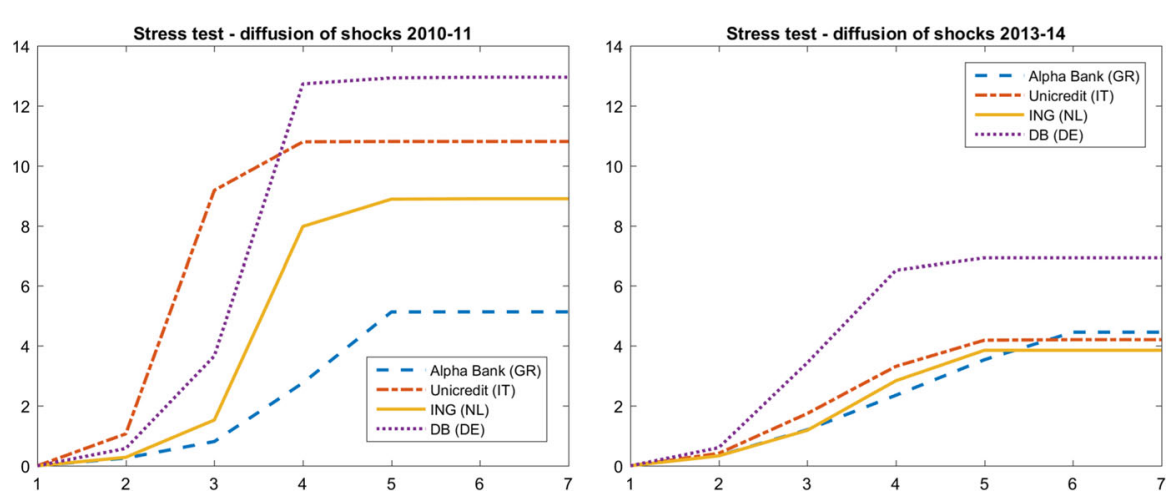

Fig. 5 Evolution of shocks in Debt Rank stress-test. We hit four different banks and we measure the amount of distress added to the system by the reverberation in the network. The x-axis represent the stages of the contagion process and $y$-axis the total level of distress. The graphs refer respectively to the periods Jan 2010-Jun 2011 and Jan 2013-Jun 2014

components links this work with the growing literature that uses machine learning techniques to study financial stability and systemic risk.

The analysis of systematic risk components highlights that in southern countries the risk affecting the banking system is largely related to both idiosyncratic components and joint country and financial factors, highlighting the role of country specific factors for financial stability, especially during the European sovereign crisis. In contrast, for banks in northern countries the role of joint country and financial shocks is limited, with financial and indiosyncratic shocks playing a more prominent role. The EU-wide factor is proportionally more relevant for northern countries.

In addition to the identification of systematic components, this work studies the non-systematic risk in a network perspective, estimating the network structure from CDS spreads data after controlling for systematic factors. The results show that banks maintain a relevant level of interconnectivity, and Spanish, German and UK banks are the most central in the system both during and after the Europaen sovereign debt crisis. We also study the potential of shock transmission by considering a simple stresstest based on the DebtRank methodology, showing that the potential for transmission was higher in the crisis period compared to the post-crisis. Moreover, the analysis highlights the fact that the structure of the network has an effect on the patterns of shock transmission. As a example, according to our contagion model a shock applied to the Italian bank Unicredit transmits faster to the rest of the system, but has a smaller overall impact compared to a shock applied to the German Deutsche Bank.

Overall, we believe that the framework proposed here could be valuable for decision makers in both regulatory bodies and financial institutions' risk management departments, allowing to decompose risk and run stress tests starting from inputs data easily available and minimal distributional assumptions. This general framework can be extended at a worldwide granular level opening a new stream of research where the intensive use of machine learning algorithms is required to approximate the centrality 
measures in order to overcome the computational complexity of these indicators in large complex networks.

Funding Open Access funding provided by Università degli studi di Bergamo.

Open Access This article is licensed under a Creative Commons Attribution 4.0 International License, which permits use, sharing, adaptation, distribution and reproduction in any medium or format, as long as you give appropriate credit to the original author(s) and the source, provide a link to the Creative Commons licence, and indicate if changes were made. The images or other third party material in this article are included in the article's Creative Commons licence, unless indicated otherwise in a credit line to the material. If material is not included in the article's Creative Commons licence and your intended use is not permitted by statutory regulation or exceeds the permitted use, you will need to obtain permission directly from the copyright holder. To view a copy of this licence, visit http://creativecommons.org/licenses/by/4.0/.

\section{Appendix: Calibration procedure}

The calibration of the model is a multi-step procedure.

- In the first phase of the process, we calibrate country and individual banks default intensities $\left(\hat{\lambda}_{C_{j}} \quad j=1, \ldots, N\right.$ and $\hat{\lambda}_{B_{i, j}}$ for every bank $i$ belonging to the country $j$, respectively) via a bootstrapping algorithm that uses CDS 5Y quotes.

- In the second phase we estimate the intensities of the common shocks with the inversion method. For example, if we consider two countries $(j, k)$, we have that their joint distribution according to our model is a bivariate exponential distribution (BVE) where the default intensity of the common shock is $\lambda_{E U}$. According to Eq. (1), starting from their historical correlation $\rho_{j, k}$, and using Eq. (1), we estimate $\lambda_{E U}$ as:

$$
\lambda_{E U_{C}}(j, k)=\frac{2\left(\hat{\lambda}_{C_{j}}+\hat{\lambda}_{C_{k}}\right) \rho_{j, k}}{3\left(1-\rho_{j, k}\right)}
$$

Note that the notation $\lambda_{E U_{C}}(j, k)$ stresses that the estimate depends on the pair of countries considered. In general, different pairs of countries determine different estimates for $\lambda_{E U_{C}}$. We follow the approach used in Baglioni and Cherubini (2013) and compute a statistic on the set of estimates. Following Farina et al. (2019), in the rest of the paper we present our results based on taking the minimum possible common component. This approach is rather conservative as it possibly underestimates the importance of common shocks. The calibration procedure is repeated for every date included in the dataset.

- In the last phase of the calibration, we retrieve the values for $\hat{\lambda}_{F_{j}} \quad j=1, \ldots, N$, according to Eq. (8).

For further details on the estimation procedure we refer the reader to Farina et al. (2019). The choice of calibrating the common components by matching implied correlation coefficients to historical ones for Marhsall-Olkin copulas finds it theoretical soundness in the work by Mazo et al. (2014) where the authors show that the statistical properties of estimators built using this strategy are robust. 


\section{References}

Acharya VV, Pedersen LH, Philippon T, Richardson M (2010) Measuring systemic risk. In: FRB of cleveland working paper series, N. 1002

Adrian T, Brunnermeier MK (2016) CoVaR. Am Econ Rev 106(7):1705-1741

Alter A, Schüler YS (2012) Credit spread interdependencies of European states and banks during the financial crisis. J Bank Finance 36(12):3444-3468

Ang A, Longstaff FA (2013) Systemic sovereign credit risk: Lessons from the U.S. and Europe, Journal of Monetary Economics60(5), 493-510,

Anufriev M, Panchenko V (2015) Connecting the dots: Econometric methods for uncovering networks with an application to the Australian financial institutions. J Bank Finance 61:S241-S255

Baglioni A, Cherubini U (2013) Within and between systemic country risk. Theory and evidence from the sovereign crisis in Europe. J Econ Dyn Control 37(8):1581-1597

Basel Committee on Banking Supervision, Basel III: A global regulatory framework for more resilient banks and banking systems, December 2010 (rev June 2011). http://www.bis.org/publ/bcbs189.pdf (2011)

Billio M, Getmansky M, Lo AW, Pelizzon L (2012) Econometric measures of connectedness and systemic risk in the finance and insurance sectors. J Financ Econ 104(3):535-559

Brownlees C, Nualart E, Sun Y (2018) Realized networks. J Appl Econom 33(7):986-1006

Cerchiello P, Giudici P (2016) Big data analysis for financial risk management. J Big Data 3(1):1-18

Covi G, Montagna M, Torri G (2019) ECB Financial Stability Review, Spring 2019

De Bruyckere V, Gerhardt M, Schepens G, Vennet RV (2013) Bank/sovereign risk spillovers in the European debt crisis. J Bank Finance 37(12):4793-4809

Diebold FX, Y1lmaz K (2014) On the network topology of variance decompositions: measuring the connectedness of financial firms. J Econom 182(1):119-134

Dumitrescu E, Banulescu DG (2014) Which are the SIFIs? A component expected Shortfall approach to systemic risk. J Bank Finance 50:575-588

Fabozzi FJ, Giacometti R, Tsuchida N (2016) The ICA-based factor decomposition of the eurozone sovereign CDS spreads. J Int Money Finance 65:1-23

Farina G, Giacometti R, De Giuli E (2019) Systemic risk attribution in the EU. J Oper Res Soc 70(7):11151128

Fontana A, Scheicher M (2016) An analysis of euro area sovereign CDS and their relation with government bonds. J Bank Finance 62(1):126-140

Freixas X, Laeven L, Peydró J (2015) MIT Press, Cambridge, MA

Gai P, Kapadia S (2010) Contagion in financial networks. Proc R Soc A Math Phys Eng Sci 466(2120):24012423

Giesecke K (2003) A simple exponential model for dependent defaults. J Fixed Income 13(3):74-83

Hurd TR (2015) Contagion! The spread of systemic risk in financial networks. Springer, Berlin

Kalbaskaa A, Gatkowskib M (2012) Eurozone sovereign contagion: evidence from the CDS market (20052010). J Econ Behav Organ 83:657-673

Kou G, Chao X, Peng Y, Alsaadi FE, Herrera-Viedma E (2019) Machine learning methods for systemic risk analysis in financial sectors. Technol Econ Dev Econ 25(5):716-742

Lichters R, Stamm R, Gallagher D (2015) Modern derivatives pricing and credit exposure analysis: theory and practice of CSA and XVA pricing, exposure simulation and backtesting. Springer, Berlin

Mai JF, Schenk S, Scherer M (2016) Exchangeable exogenous shock models. Bernoulli 22(2):1278-1299

Manzo G, Picca A (2020) The Impact of Sovereign Shocks. Manag Sci 66(7):3113-3132

Marshall AW, Olkin I (1967) A multivariate exponential distribution. J Am Stat Assoc 62(317):30-44

Mazo G, Girard S, Forbes F (2014) Weighted least square inference based on dependence coefficients for multivariate copulas. In: Compstat, 21st symposium of the IASC. Geneve, Suisse

Newman M (2010) Networks: an introduction. Oxford University Press, Oxford

O'Halloran S, Nowaczyk N (2019) An artificial intelligence approach to regulating systemic risk. Front Artif Intell 2:1-14

O'Halloran S, Maskey S, McAllister G, Park DK, Chen K (2015) Big data and the regulation of financial markets. In: Proceedings of the 2015 IEEE/ACM international conference on advances in social networks analysis and mining, pp 1118-1124 (2015)

Pianeti R, Giacometti R (2015) Estimating the probability of multiple EU sovereign defaults using CDS and bond data. Quant Finance 15(1):61-78 
Puliga M, Caldarelli G, Battiston S (2014) Credit default swaps networks and systemic risk. Sci Rep 4(1):1-8 Reboredo JC, Ugolini A (2015) Systemic risk in European sovereign debt markets: a CoVaR-copula approach. J Int Money Finance 15:214-44

Schwarcz S (2008) Systemic risk. Duke Law School Legal Studies Paper No. 163 97(1)

Torri G, Giacometti R, Paterlini S (2018) Robust and sparse banking network estimation. Eur J Oper Res 270(1):51-65

Wayne DW (1990) Applied nonparametric statistics, 2nd edn. PWS-Kent, Boston

Yu J, Zhao J (2020) Prediction of systemic risk contagion based on a dynamic complex network model using machine learning algorithm. Complexity

Publisher's Note Springer Nature remains neutral with regard to jurisdictional claims in published maps and institutional affiliations.

\section{Affiliations}

\section{R. Giacometti ${ }^{1,2}$ (D) G. Torri ${ }^{1,2} \cdot$ G. Farina ${ }^{3} \cdot$ M. E. De Giuli ${ }^{4}$}

G. Torri

gabriele.torri@unibg.it

G. Farina

gianluca.farina@mediobanca.com

M. E. De Giuli

elena.degiuli@unipv.it

1 Department of Economics, University of Bergamo, Via dei Caniana 2, 24127 Bergamo, Italy

2 VŠB Technical University of Ostrava, Sokolská tř. 33, 70200 Ostrava, Czech Republic

3 Mediobanca S.P.A, Milan, Italy

4 Department of Economics and Management, University of Pavia, Corso Str. Nuova, 65, 27100 Pavia, Italy 